\title{
Cindy Sherman e o posicionamento de Untitled \#264 em sua produção artística
}

\begin{abstract}
Aline Rena ${ }^{1}$
Resumo: Este artigo pretende apresentar de forma concisa as diversas séries fotográficas da artista visual americana Cindy Sherman (1954), questionando, com base em entrevistas, artigos críticos, catálogos de exposições e livros sobre o trabalho da artista publicados ao longo de sua carreira, o posicionamento atualmente consolidado da obra Untitled \#264 (1992) na série sex pictures.

Palavras-chave: Corpo. Fotografia. Feminino. $\mathrm{Nu}$.
\end{abstract}

\section{Cindy Sherman and the positioning of Untitled \#264 in her artistic production}

\begin{abstract}
This article intends to present in a concise way the various photographic series of the American visual artist Cindy Sherman (1954), questioning, based on interviews, critical articles, exhibition catalogs, and books about the artist's work published throughout her career, the currently consolidated position of Untitled \# 264 (1992) in the sex pictures series.
\end{abstract}

Keywords: Body. Photograph. Feminine. Nude.

${ }^{1}$ Aline Rena é formada em Matemática com especialização em Informática pela Universidade do Estado do Rio de Janeiro (UERJ), pós-graduada em Redes de Computadores pela PUC-Rio e bacharel em História da Arte também pela UERJ. Dedica-se ao estudo de trabalhos de artistas mulheres, em especial aqueles relacionados à questão da representação do feminino. 


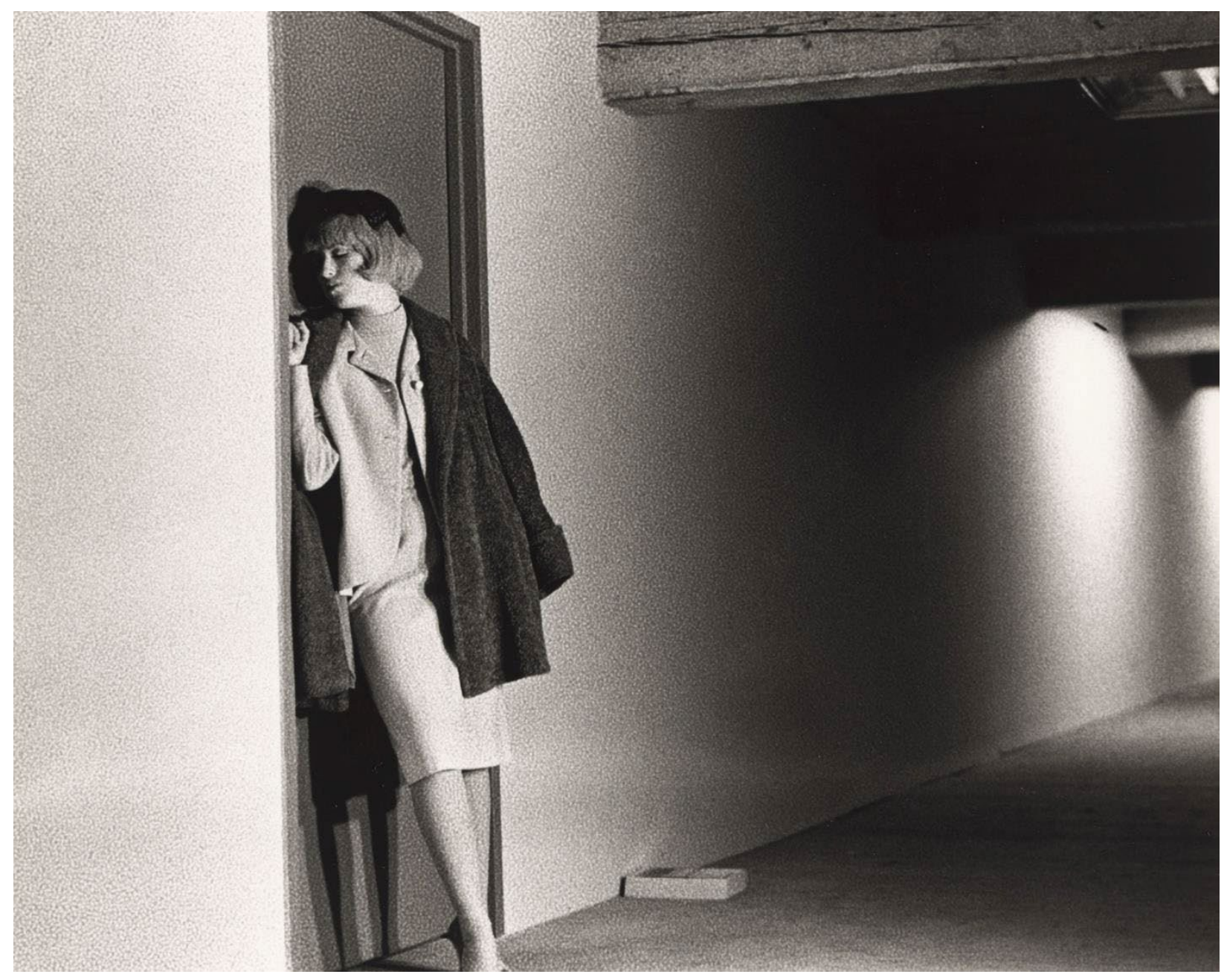

Fig. 1: Cindy Sherman, Untitled Film Stills \#4, 1977. Impressão em gelatina de prata, $19,2 \mathrm{~cm}$ x $24 \mathrm{~cm}$, The Museum of Modern Art. Nova Iorque. Fonte: MoMA.

Na primeira metade da década de 1970, as artistas americanas Lynda Benglis, Eleanor Antin e Hannah Wilke utilizaram o próprio corpo como suporte para ensaios fotográficos que contribuíram para acirrar o debate feminista sobre a representação da mulher e do nu feminino nos meios de comunicação de massa fortemente presentes nos Estados Unidos à época, como o cinema, a televisão, os jornais, as revistas e os comerciais ${ }^{1}$. Seus trabalhos tornaram-se fortes referências para uma geração de artistas que estava em formação naquele país, entre eles a também americana Cindy Sherman. 
Nascida em 1954 em Nova Jersey, Sherman iniciou sua graduação em pintura na Universidade do Estado de Buffalo em 1972. Ainda na faculdade, passou a se interessar por fotografia, por artistas conceituais e pelos que lidavam com performance, o que a levou a abandonar rapidamente a pintura. Começou a aparecer em público encarnando personagens que inventava e construía com maquiagens, perucas e roupas diversas, uma prática que remontava às suas brincadeiras de infância ${ }^{2}$ e que se tornaria o pilar dos seus trabalhos como artista visual, conforme declarou em entrevista à rede de televisão britânica BBC em 1994:

[...] lembro de uma foto minha quando eu tinha provavelmente uns 10 anos de idade [...] eu colocava os vestidos antigos da minha avó ou da minha bisavó e toda a maquiagem era para parecer como uma senhora de idade ${ }^{3}$.

Desde o início da sua produção artística na segunda metade da década de 1970, Sherman procurou explorar as convenções dos meios de comunicação de massa produzindo trabalhos que questionavam o impacto gerado por esses meios na forma como os indivíduos se imaginam nas sociedades urbanas ${ }^{4}$. A artista assume que grande parte da sua inspiração vem de influências da mídia em volta dela, algo que não chega a surpreender, já que ela faz parte da primeira geração americana que cresceu assistindo à televisão o tempo todo 5 .

Embora produza fotografias, Sherman não pode ser chamada de fotógrafa, tampouco está interessada em explorar a técnica da fotografia à exaustão. Atuando como produtora, figurinista, cenógrafa, maquiadora, cabeleireira e modelo das próprias fotos e valendo-se de recursos como fantasias, perucas, maquiagem e todo tipo de adereço, dos prosaicos aos mais sofisticados ${ }^{6}$, a artista vê a câmera como uma entre dezenas de ferramentas à sua disposição. Nas palavras de Sherman à BBC:

É apenas uma ferramenta [...] poderia ser um pincel, exceto pelo fato de que demoraria muito para obter as imagens que eu gostaria de fazer. Dessa forma, em segundos eu as tenho. [...] Posso, então, investir todo o tempo no que a imagem deve ser e usar a câmera para capturar essa imagem. ${ }^{7}$

Mais recentemente, a artista tem explorado aplicativos de edição de imagens para telefones celulares e a publicação na rede social Instagram das fotos produzidas por meio deles ${ }^{8}$.

Podemos dizer então que Sherman é uma artista que usa a câmera como recurso para registrar suas personagens. Assim como a tela é o meio específico da pintura, o corpo de Sherman (e não a 
fotografia) seria, portanto, o meio de fato para a expressão de seu trabalho ${ }^{9}$. Produzindo sozinha em seu estúdio a maior parte do tempo, a artista mantém o controle sobre todo o seu processo criativo. O caráter autossuficiente e isolacionista de seu trabalho vai além disso: sua própria figura tem destaque nas fotos que produz (raramente a artista não está presente nessas fotos ${ }^{10}$ ) e, não por acaso, a mulher solitária nelas tem papel central ${ }^{11}$. Sherman nega veementemente, entretanto, que as fotos que produz sejam autorretratos ou mesmo que façam qualquer referência à sua personalidade $^{12}$ e justifica o uso de si própria como modelo pela praticidade e por não gostar de trabalhar com outras pessoas ${ }^{13}$. Em entrevista ao diretor de cinema e fotógrafo John Waters, em 2012, a artista declarou ter tentado, em meados da década de 1980, contratar modelos e até mesmo fotografar membros da família e amigos. Entretanto, no início de sua carreira na década de 1970, usar a si mesma como modelo foi, acima de tudo, uma forma de fazer o que bem quisesse sem precisar mostrar seu trabalho a ninguém ${ }^{14}$.

Sherman é uma das artistas americanas mais comentadas de sua geração, sendo extensa a lista de publicações e críticos que discutem sua obra ${ }^{15}$. Para alguns deles, o foco do trabalho da artista está na questão da identidade alheia, para outros, na exploração da identidade da própria artista, já alguns veem na identidade algo irrelevante para o entendimento do seu trabalho ${ }^{16}$. Para a crítica de arte Eva Respini - responsável pela curadoria de uma das maiores retrospectivas da artista, realizada em 2012 no Museu de Arte Moderna de Nova Iorque (MoMA) -, "Sherman foi uma das grandes protagonistas da nova geração de artistas americanos que usaram a fotografia para repensar radicalmente a mídia em um mundo de saturação visual cada vez maior"17. A artista, entretanto, se distancia das críticas. "Teorias, teorias, teorias... Parece que elas não funcionam comigo", escreveu Sherman em um caderno de anotações em $1997^{18}$. Ou ainda, na supracitada entrevista à BBC: "Não tenho muito interesse em tudo isso que escrevem sobre o meu trabalho, a não ser por pura curiosidade mesmo" ${ }^{19}$.

Sua primeira série intitulada Untitled Film Stills (1977 a 1980), em que estereótipos femininos com forte referência cinematográfica são retratados em fotografias em preto e branco (fig. 1), a alçou à posição de uma das artistas mais influentes de sua geração e é hoje um trabalho 
“canonizado" por curadores, críticos de arte e historiadores ${ }^{20}$. Em 1995, a série completa com 69 fotografias foi adquirida pelo MoMA por aproximadamente um milhão de dólares ${ }^{21}$.

Foi, porém, com a série conhecida como centerfolds (1981) que Sherman viu sua obra ser fortemente reconhecida internacionalmente, após ser exibida na Documenta de Kassel de 1982 e na Bienal de Veneza do mesmo ano ${ }^{22}$. Em centerfolds, a artista deixou de lado a nostalgia dos anos 1950 experimentada na série Untitled Film Stills, voltando-se para uma mídia contemporânea: as publicações em forma de revista. Apropriando-se do formato horizontal e centralizado das fotos de modelos do tipo pin-up publicadas em páginas duplas de revistas masculinas, Sherman encarnou personagens que jamais seriam encontrados nessas publicações, começando pelo fato de que as mulheres não estão nuas ou seminuas e passando pela ironia da artista exercer tanto o papel da modelo, quanto o do fotógrafo ${ }^{23}$, livre, portanto, para escolher como queria ser representada.

Diante do sucesso vertiginoso alcançado pela série centerfolds - também acompanhado por uma forte polêmica envolvendo grupos feministas ${ }^{24}$ - a artista decidiu desafiar seu público com trabalhos produzidos de forma em que sua imagem como "Cindy Sherman" não fosse imediatamente reconhecida nelas ${ }^{25}$. A série conhecida como fairy tales (1985) marca o início do uso de próteses ${ }^{26}$, como narizes, bocas, queixos, acnes e até línguas falsas, que alteravam significativamente seu rosto nas imagens. Em cenas que lembram a fantasia, o suspense e o horror do conteúdo dos "contos de fadas originais", Sherman faz referência a esse universo sem se ater a qualquer conto específico ${ }^{27}$. É, ainda, em fairy tales, que a representação do nu aparece pela primeira vez na obra da artista, novamente por meio do uso de próteses, como seios e nádegas falsas $^{28}$ (fig. 2). 


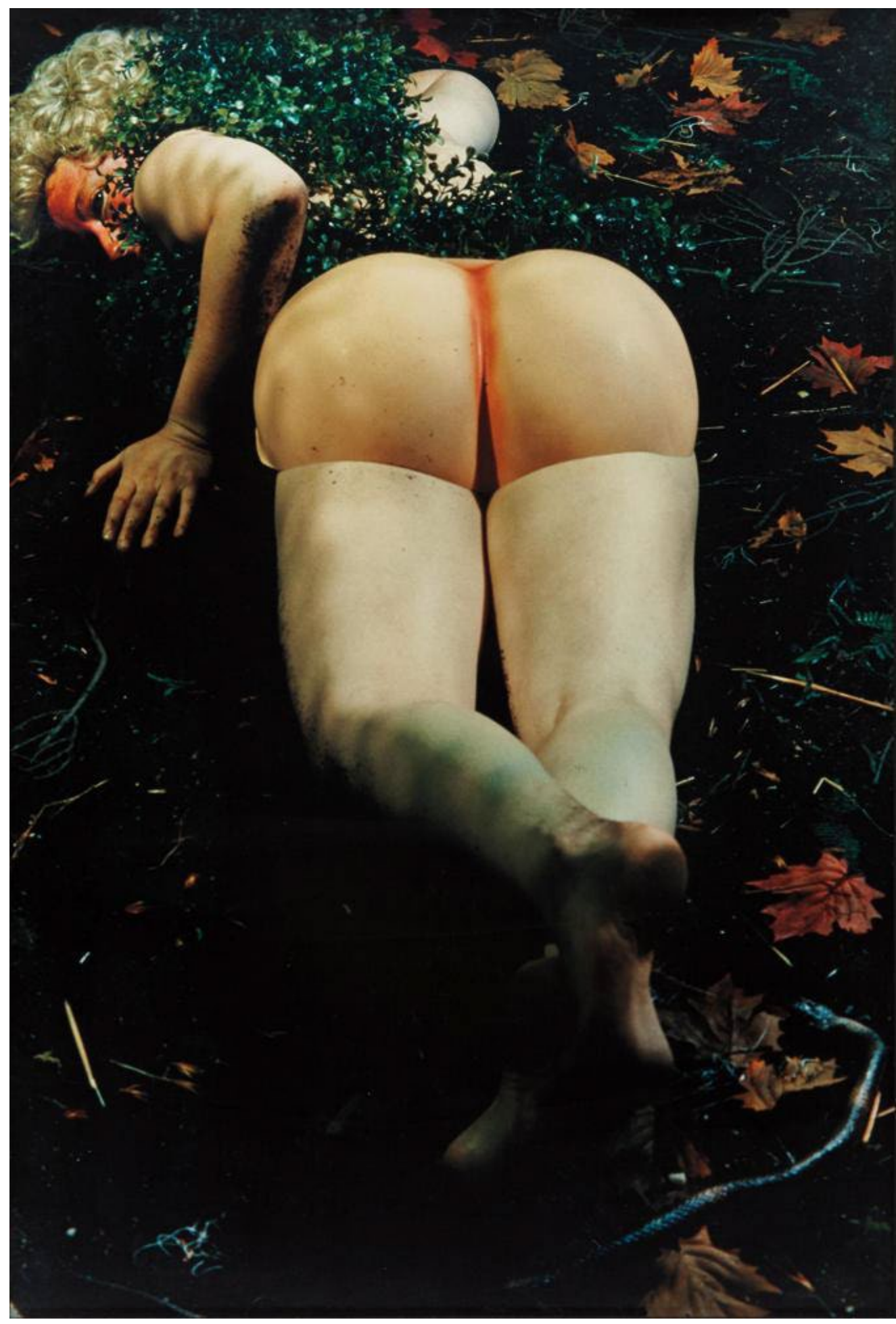

Fig. 2: Cindy Sherman, Untitled \#155, 1985. Impressão colorida, 184,2 cm x 125,1 cm, Per Skarstedt Fine Art, Nova Iorque. Fonte: Ocula. 
Tal desafio proposto por Sherman foi às últimas consequências na série conhecida como disasters ou vomit pictures (1986 - 1990), em que a figura da artista deixou de ocupar o centro da obra, aparecendo na maior parte das vezes apenas em pequenos pontos de imagens produzidas com objetos do cotidiano parcialmente destruídos e sujos, restos de comida, lixo, insetos falsos, terra remexida, roupas em mau estado e toda sorte de material organizada de forma a remeter à desordem, ao caos, à morte, à decadência e ao repugnante. Em alguns trabalhos, a figura de Sherman chega a desaparecer por completo.

Embora ricas em cores, em texturas e em composição, são fotografias, que, à época, a artista supunha que "ninguém ousaria gostar" ${ }^{29}$ ou "ter coragem pendurar em cima do sofá" 30 . Sherman declarou a importância dessa rejeição do público ao seu trabalho na medida em que isso a ajudaria a aliviar seu sentimento de culpa pela forma como suas fotografias foram recebidas pelo sistema de $\operatorname{artes}^{31}$ desde a série Untitled Film Stills, recepção essa marcada pela rápida aceitação tanto por parte dos críticos quanto dos colecionadores ${ }^{32}$, algo que a artista jamais esperou em sua carreira ${ }^{33}$. Por outro lado, havia uma certa preocupação por parte de Sherman com a dependência de sua própria figura na obra, de forma que a artista se propôs a experiência de "contar uma história ou fazer uma imagem sem incluir a si própria" 34 .

A série history portraits (1990) marcou o retorno contundente da artista como modelo no centro de sua obra, porém de uma forma completamente diferente dos trabalhos anteriores. Usando como referência retratos de época, bem como imagens de temas clássicos da pintura a óleo europeia nas quais a figura humana era protagonista (como a Virgem e o Menino, por exemplo), Sherman produziu releituras que, salvo algumas exceções, não se atêm a um ou outro quadro ou artista específico, mas que prontamente reconhecemos como imagens que ocupam as paredes dos grandes museus ocidentais. Nelas, seu rosto está drasticamente alterado pelo uso de próteses faciais, perucas, cosméticos e toda sorte de artifícios de maquiagem, de forma que é praticamente impossível reconhecer a artista nessas imagens. Em algumas, próteses de seios - que já haviam sido exploradas na série fairy tales - voltam à cena com força total (fig. 3). Essa é, ainda, uma das poucas séries em que a artista se retrata como homem. 


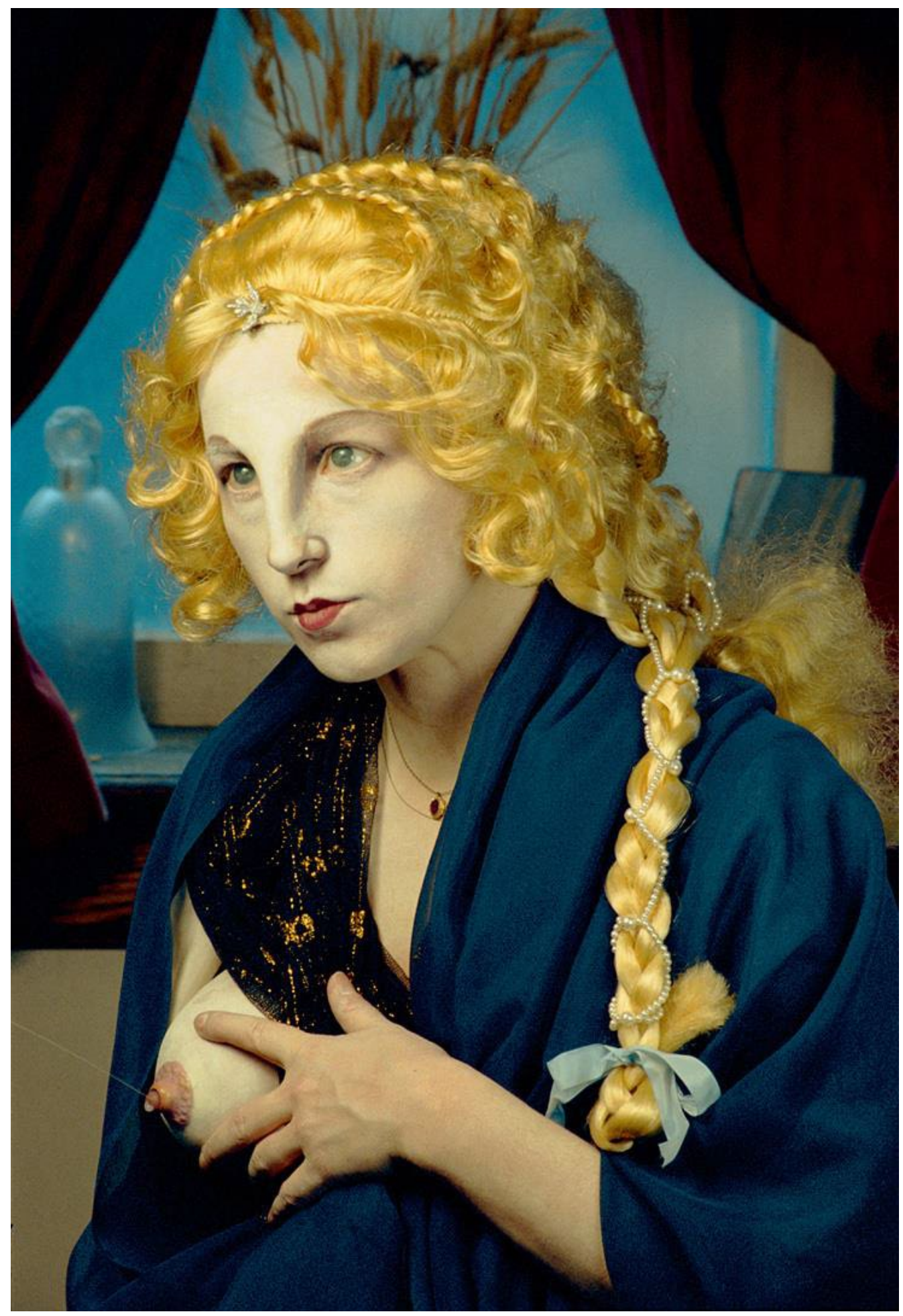

Fig. 3: Cindy Sherman, Untitled \#225, 1985. Impressão colorida, 121,92 cm x 83,82 cm, The Broad Collection, Los Angeles. Fonte: The Broad. 
Embora estivesse ciente dos altos níveis de popularidade que as fotografias de history portraits poderiam atingir, a reação do público e o sucesso alcançado pela série assustou Sherman em um nível sem precedentes. Foi nessa ocasião que a artista decidiu produzir uma série de fotografias em que, mais uma vez, sua figura desapareceu do trabalho, dando lugar a manequins e próteses de partes do corpo humano, adquiridas dessa vez por meio de catálogos médicos ${ }^{35}$. Além disso, Sherman percebeu que vivia um momento em que precisava abordar a temática da sexualidade e da censura, sem comprometer seus valores ${ }^{36}$. A série ficou conhecida como sex pictures $(1992)^{37}$ e uma de suas características mais marcantes é a presença de corpos humanos híbridos, estéreis e desconjuntados. Para discuti-la, contudo, é de suma importância uma pausa para debruçarmo-nos sobre acontecimentos da década 1980 que influenciaram diretamente sua produção.

Em 1981, foram observados nos Estados Unidos os primeiros casos clínicos de uma doença mortal que seria batizada um ano depois como AIDS (Acquired ImmunoDeficiency Syndrome). Manifestando-se inicialmente em usuários de drogas injetáveis e homens homossexuais, a doença chegou a ser chamada pela imprensa de GRID (gay-related immune deficiency), "doença gay" e, ainda, "câncer gay", até que casos fora desses grupos de indivíduos foram detectados, fazendo com que tal denominação perdesse o sentido. Embora não mais restrita aos gays, a doença já havia sido associada pela sociedade a eles, já que o vírus - isolado em 1986 e denominado HIV (Human Immunodeficiency Virus) - se disseminava com mais facilidade por meio de relações homossexuais entre homens. Com origem no continente africano, o HIV chegou às Américas pela primeira vez no Haiti e acredita-se que um único indivíduo desconhecido o tenha levado para os Estados Unidos, contaminando homens homossexuais americanos, especialmente os residentes em Nova Iorque e São Francisco ${ }^{38}$, cidades com uma grande quantidade de artistas visuais gays, muitos deles vítimas fatais da doença nessa década e na seguinte ${ }^{39}$.

Uma onda de conservadorismo invadiu os Estados Unidos, espalhando o medo em relação ao sexo e associando a AIDS a determinadas práticas sexuais consideradas "anormais" (especialmente pela Igreja Católica), já que envolviam troca de fluidos corporais por meio dos orifícios oral e anal do corpo $^{40}$. Somado a isso, artistas de todo o país encontravam-se extremamente fragilizados e sensibilizados pelo fato de que seus colegas e amigos pessoais estavam morrendo de AIDS. 
Incentivos físcais do governo americano a determinados trabalhos artísticos começavam a ser questionados, levando a uma espécie de censura velada. A temperatura do debate aumentou após o cancelamento, em 1989, da retrospectiva The perfect moment do fotógrafo Robert Mapplethorpe pela Corcoran Gallery of Art, meses após a morte do artista, justamente em decorrência de complicações por conta da $\operatorname{AIDS}^{41}$.

Nesse contexto, sentindo que não precisava se preocupar com uma possível censura ao seu trabalho, uma vez que poderia arcar com as despesas de sua produção e exibição, especialmente após o sucesso estrondoso alcançado pela série anterior ${ }^{42}$, Sherman deu início à produção de $\operatorname{sex}$ pictures. Nas palavras da artista à $\mathrm{BBC}$ :

Estive pensando que o passo perfeito para eventualmente trabalhar com essas partes de corpos, considerando todas as sugestões sutis de nudez no meu trabalho ao longo dos anos 80 , seria abordar a sexualidade e, quem sabe, a pornografia. A AIDS, claro, tem que ser de alguma forma discutida hoje em dia quando se fala ou mostra qualquer coisa sexual. Além disso, a censura por volta de 1990 tornou-se um grande problema neste país. Então, a série de fotografias em que uso as partes de corpos foi, de certa forma, uma resposta ao debate sobre a censura dentro do National Endowment for the Arts aqui nos Estados Unidos, que se tornou um grande problema quando o NEA retirou o financiamento de alguns projetos de arte controversos. ${ }^{43}$

A obra Untitled \#264 (fig. 4), objeto deste artigo, foi produzida em 1992 e é, portanto, inserida historicamente na série sex pictures. Trata-se de um dos trabalhos mais provocativos da artista, ao qual cabe, neste momento, um convite para um olhar mais atento. $\mathrm{Na}$ imagem de formato horizontal, pernas e pés de um manequim vestidos com uma meia fina preta, uma prótese de seios femininos fartos, claros e com mamilos escuros, um objeto rosado que lembra uma vulva, uma mão branca com longas unhas vermelhas, uma cabeça humana com uma peruca loira, uma coroa dourada e o rosto coberto por uma máscara negra de couro formam um corpo feminino nu, parcialmente envolto em um tecido de cetim magenta e brilhante. Reclinado ao longo do eixo horizontal da imagem sobre esse mesmo tecido, o corpo ocupa a grande totalidade da imagem. 


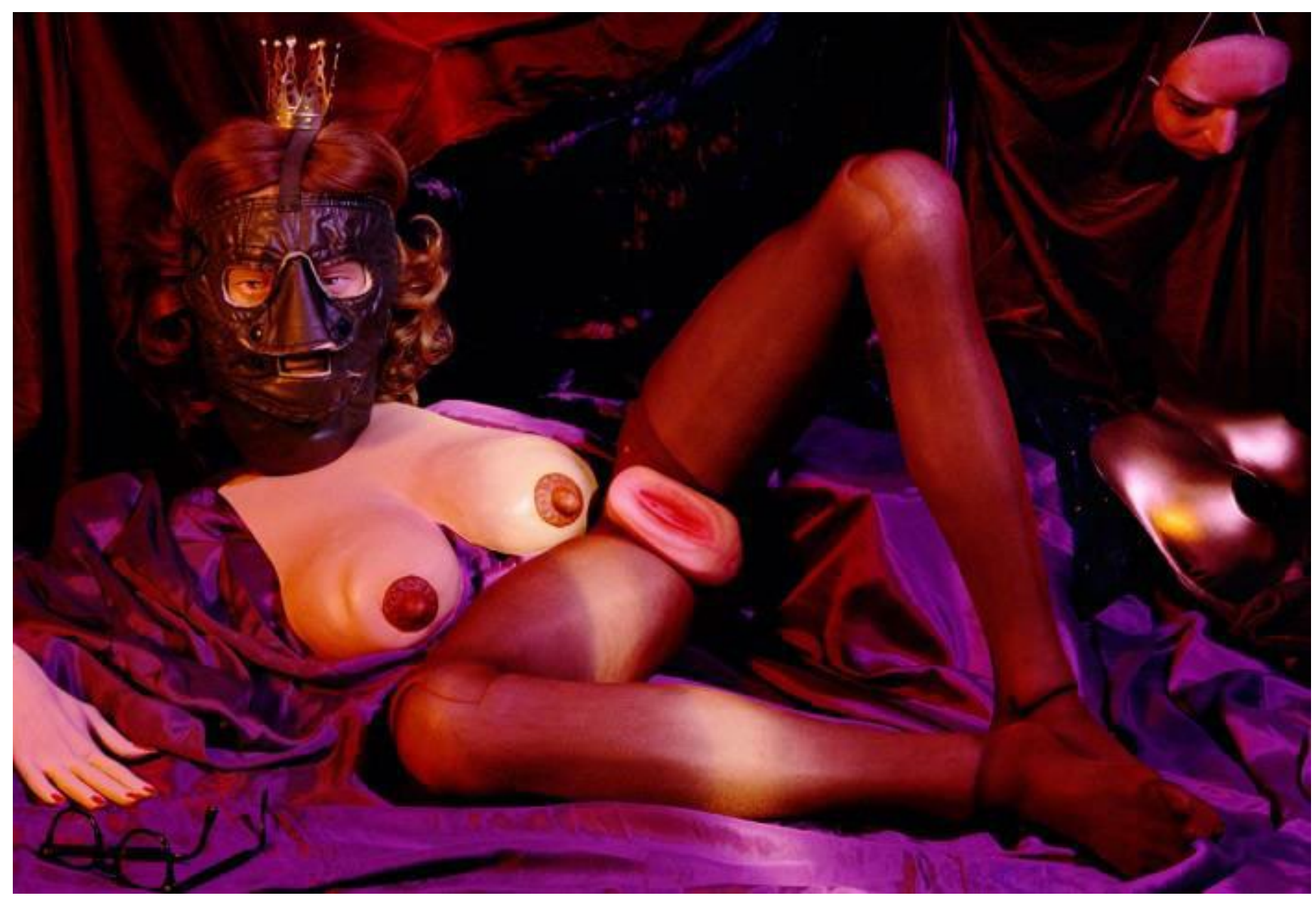

Fig. 4: Cindy Sherman, Untitled \#264, 1992. Impressão colorida, $127 \mathrm{~cm}$ x $190.5 \mathrm{~cm}$, The Broad Collection, Los Angeles. Fonte: The Broad.

Um tecido de cor escura pende em sentido vertical ao fundo, como uma espécie de cortina, parcialmente aberta no centro da composição. Na parte inferior esquerda da imagem, uns óculos de grau pretos estão pousados ao lado da mão sobre o tecido de cetim. No lado extremo direito da imagem, uma máscara em formato de rosto humano aparece sobreposta ao tecido do fundo, pendurada pelo elástico que serviria para prendê-la a uma cabeça. Seus olhos estão voltados para baixo, onde repousa uma espécie de armadura cor de cobre em formato de seios femininos, com o que parecem ser buracos no lugar dos mamilos. 
A imagem é escura em quase toda sua totalidade, com iluminação fraca e uniforme, exceto por um feixe de luz em diagonal que vai da panturrilha da perna direita passando pela coxa da mesma perna, pelo seio esquerdo, pelos cachos da peruca e culminando na coroa sobre a cabeça. No centro da composição, o objeto que faz a vulva tem lugar de destaque entre as duas pernas abertas de forma quase a encostar na prótese dos seios.

Como uma espécie de herança de Untitled \#264, manequins, próteses e máscaras continuaram a ser amplamente utilizados nas fotografias produzidas pela artista após a série sex pictures.

Eu ainda estava trabalhando com manequins, não estava usando a mim mesma como modelo. Além disso, queria trazer de volta a ideia de acaso. Estava movendo a câmera, então algumas imagens estão borradas e duplamente expostas ${ }^{44}$,

declarou Sherman a Waters em 2012. É o caso de Untitled \#323, da série conhecida como masks (1995 - 1996): olhos humanos (possivelmente os olhos da artista) encaram o observador. Da esquerda para a direita, um rosto humano carregado de maquiagem brilhante se transmuta em uma máscara em que o olho direito, bruscamente cortado da imagem, não se encaixa com precisão no espaço reservado a ele. A máscara tornou-se, assim, o tema central do trabalho, ocupando toda a imagem e evocando constantemente tanto a presença quanto a ausência da $\operatorname{artista~}^{45}$. O trabalho é assustador, refletindo, talvez, o interesse declarado de Sherman por filmes de terror ${ }^{46}$ e pela obra do Marquês de $\mathrm{Sade}^{47}$.

Produzidas no mesmo período, as fotografias da série conhecida como horror and surrealist pictures (1994 - 1996) são vistas como uma extensão da série sex pictures, na medida em que a artista intensifica o uso de corpos nus artificiais compostos por manequins e próteses ${ }^{48}$. Seu nome faz referência à associação do arranjo fantástico e provavelmente impossível dos corpos nas imagens - como podemos observar em Untitled \#312 (fig. 5) - com trabalhos de artistas surrealistas da primeira metade do século $\mathrm{XX}^{49}$, em especial as bonecas (La poupéés) do artista alemão Hans Bellmer (1902 - 1975). Entretanto, produzindo em um contexto social de massificação e valorização de cirurgias plásticas, de uso excessivo de cosméticos e de todo tipo de alteração do corpo, Sherman, atualizou o processo surrealista de dar vazão ao pensamento irracional com a cultura contemporânea ${ }^{50}$. 


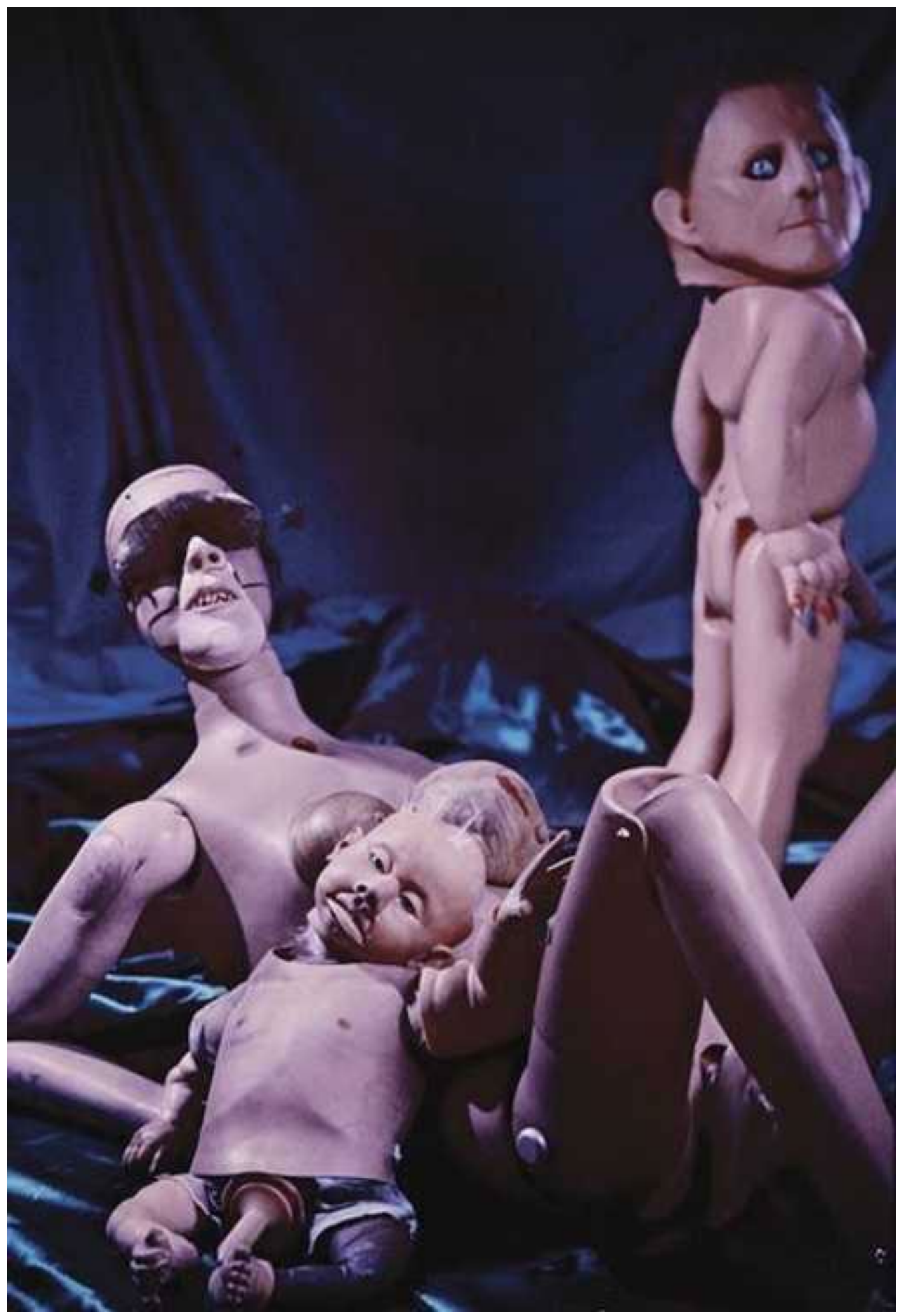

Fig. 5: Cindy Sherman, Untitled \#312, 1994. Impressão colorida, 154,9 cm x 105,4 cm, Metro Pictures, Nova Iorque. Fonte: Mynewsdesk. 
Houve, ainda, na virada do século, uma intrigante série produzida e exibida na galeria Metro Pictures, em Nova Iorque, em 1999. Ignorada por grande parte dos críticos, sequer há um consenso em relação ao seu nome, embora seja referenciada aqui e ali como broken dolls. Nessa série, a artista retornou pela primeira vez desde Untitled Film Stills às fotografias em preto e branco. Corpos de bonecas e bonecos reais aparecem mutilados, rasgados, carbonizados, desconjuntados e amontoados em poses eróticas em imagens de formato menor que o comumente utilizado por Sherman ${ }^{51}$, configurando-se em um terrível pesadelo de infância ${ }^{52}$. A conexão com as bonecas de Bellmer é ainda mais evidente, o que será discutido mais detalhadamente adiante neste artigo.

Cindy Sherman mantém um método de nomear suas obras com a palavra Untitled, seguida do símbolo \# e de um número sequencial, sem qualquer descrição adicional que remeta ao assunto da fotografia. Inevitavelmente, uma série de trabalhos com temática semelhante e produzida em um determinado espaço temporal acaba sendo conhecida por um nome que faz alusão a essa temática, seja esse nome fruto de um consenso entre os críticos ou de declarações da própria artista em entrevistas ${ }^{53}$.

Dessa forma, a obra Untitled \#264 é referenciada bibliograficamente como parte da série datada de 1992 (sex pictures), conforme já mencionado neste artigo. Embora essa seja uma espécie de classificação bastante confortável, proponho aqui outra leitura, baseada nas séries anteriormente produzidas por Sherman bem como em um olhar retrospectivo à sua obra, sugerido por pelo menos quatro respeitados críticos de arte que se debruçaram sobre a obra da artista, dentre eles a americana Rosalind Krauss. A crítica encerra seu ensaio intitulado "Cindy Sherman: Untitled"54, de 1993, afirmando que a coerência do trabalho da artista é algo que surge de um exame retrospectivo, já que cada nova série parece se dobrar sobre e comentar as séries anteriores. Krauss vai além:

No momento em que este texto for para a gráfica, Sherman estará, sem dúvida, produzindo um novo trabalho. Nele, ou no próximo, encontraremos significantes que irão atravessar o horizonte discursivo e o plano da imagem ${ }^{55}$ para reforçar e esclarecer o que está escondido na última série apresentada ao público ${ }^{56}$.

Já a britânica Laura Mulvey, depois de uma análise da obra da artista até a série disasters, propõe em "Cosmetics and abjection: Cindy Sherman 1977 - 87" $(1991 / 1996)^{57}$, a releitura da série Untitled Film Stills baseada no desenvolvimento dos trabalhos posteriores ${ }^{58}$. A crítica também 
afirma que o visitante de uma exposição retrospectiva da artista que chegue às imagens finais e volte ao início de trás para frente descobrirá que, tendo a percepção do que estava por vir, as imagens iniciais se transformam ${ }^{59}$.

Ao comparar duas imagens da série Untitled Film Stills em "House of Wax" (1993)", o crítico americano Norman Bryson conclui ser necessário virar as páginas da "obra completa" da artista para se ter uma percepção estrutural de ambas as imagens. Essa conclusão, juntamente com as de Krauss e Mulvey, é mencionada pela americana Johanna Burton, a mais jovem dos quatro críticos, no início de seu ensaio "A body slate: Cindy Sherman" "61, de 2004:

Embora seus ensaios [...] nos apresentem narrativas discordantes [...], eles concluem com um palpite: 0 espectador encontrará traços do trabalho mais recente acenando para o trabalho mais antigo, caso leia as diversas séries da artista de forma retrospectiva ${ }^{62}$.

Valendo-me, assim, do olhar retrospectivo à obra de Sherman partindo de 1999, bem como da análise de sua produção antes de 1992, proponho que Untitled \#264 seja percebida como uma obra que perpassa diversas séries da artista.

Da série centerfolds, a imagem toma emprestado o formato horizontal, herdado das páginas de revistas e das telas wide-screen, formato consistentemente explorado por Sherman pela primeira vez nessa série. Embora o significante ${ }^{63}$ da imagem em Untitled \#264 não seja o ponto de vista da câmera (de cima para baixo), comum às imagens da série centerfolds ${ }^{64}$, sua horizontalidade pode ser lida como uma forma de contestação da verticalidade presente na história da arte por meio da pintura de cavalete moderna, contestação que já havia sido feita antes por artistas pós-modernos como Andy Warhol e Robert Morris ${ }^{65}$.

Para Sherman, a horizontalidade de centerfolds era, de fato, sua característica mais instigante e toda sua extensão deveria ser preenchida, algo que uma figura reclinada permite ${ }^{66}$. Outra intenção declarada de Sherman para essa série era colocar o observador em uma posição de constrangimento por se perceber invadindo um espaço que não deveria, o espaço onde encontra-se uma mulher deitada $^{67}$. Ora, a representação em Untitled \#264 é exatamente a dessa figura reclinada, cujo espaço privado é invadido por um suposto observador dentro da cena, que espia o recinto por trás de uma porta entreaberta, evidenciada pela fresta de luz vertical encontrada no centro da imagem. 
Da série fairy tales, Untitled \#264 herda o uso de próteses. Embora as próteses utilizadas nessa série não fossem médicas como as de Untitled \#264, para o crítico americano Hal Foster, elas são responsáveis, em grande medida, pela introdução do grotesco à obra de Sherman. Com a ajuda desse artifício, a artista foi capaz de alterar seu rosto em fairy tales a ponto de se tornar irreconhecível em figuras com "terríveis acidentes de nascença ou aberrações da natureza (como uma jovem com um focinho de porco ou uma boneca com a cabeça de um velho sujo)" ${ }^{\text {, }}$, comparáveis a "seres mitológicos híbridos" "99 Por essa via, com o uso de próteses exacerbado a ponto de construir um corpo completamente artificial, a figura em Untitled \#264 pode ser considerada grotesca, conectando-se, então, às imagens de fairy tales. Além disso, o uso do nu, inaugurado também nessa série, é outro elemento de forte ligação entre fairy tales e Untitled \#264.

Da série disasters (ou vomit pictures), Untitled \#264 herda a ausência da figura da artista na obra. Tal ausência pode ser vista como parcial, se considerarmos que o rosto por trás da máscara é de Sherman, ou total, se considerarmos que, assim como o restante do corpo, esse rosto também é artificial. Se optamos pela primeira hipótese, a conexão com disasters é estabelecida na medida em que, mesmo nas imagens dessa série em que a figura da artista aparece, sua presença encontrase em detalhes, que, em Untitled \#264, seriam os olhos e a boca por trás da máscara. Se optamos pela segunda hipótese, a conexão se dá pela ausência total de Sherman na imagem, característica de boa parte das fotografias dessa série e ponto de extrema importância na carreira da artista, por motivos diversos discutidos anteriormente neste artigo.

De todas as séries anteriores a sex pictures, history portraits talvez seja a que estabelece um diálogo mais direto com Untitled \#264. Diante da imagem da obra, é inevitável não associá-la às inúmeras representações em pintura a óleo da clássica pose de nu feminino conhecida como "Vênus reclinada". Untitled \#264 não possui algumas características do gênero de pintura conhecido como retrato, como o formato vertical, por exemplo, presente em todos os outros trabalhos série history portraits. Entretanto, a pose da "Vênus reclinada" foi extensamente utilizada para retratar mulheres ao longo da história da arte, ainda que, na grande maioria das vezes, os títulos atribuídos aos quadros não fizessem qualquer referência aos nomes dessas mulheres, como é o caso da pintura Vênus de Urbino, de Ticiano. 
Outro diálogo também se estabelece com history portraits quando pensamos na crítica de Rosalind Krauss às obras dessa série. Para Krauss, as próteses em history portraits podem ser pensadas como espécies de

véus ou máscaras, elementos que marcam a superfície da imagem e que, portanto, deveriam ser retirados, deixados de lado, e, na sua própria capacidade de desvinculação, apontariam para a dimensão hermenêutica da obra de arte: a ideia de que ela possui uma verdade interior ou um significado no qual o intérprete deveria penetrar $^{70}$.

Embora Untitled \#264 também faça uso de próteses, é na máscara cobrindo o rosto (de Sherman?) que encontraríamos esse elemento de delimitação da superfície, compelindo-nos ao impulso de removê-lo para que a verdade por trás da obra seja revelada.

A máscara é ainda um recurso que pode ser visto como elemento de ligação entre history portraits e a série conhecida pelo nome masks, posterior à sex pictures. Além de cobrir o rosto que compõe o corpo feminino, aparece ainda na parte superior direita da imagem. O uso de máscaras não era novidade para a artista quando a série masks foi produzida. Além de Untitled \#264, elas apareceram pontualmente em trabalhos anteriores, como Untitled \#228 e Untitled \#250. Porém, Untitled \#264 é o único desses trabalhos em que a máscara cobre um rosto humano deixando visíveis apenas sua boca e seus olhos, antecipando, assim, o que se tornaria o significante da série masks: o olhar que encara fixamente o observador ${ }^{71}$.

Se ainda hoje se discute se o rosto por trás da máscara em Untitled \#264 é ou não de Sherman, uma vez que a artista não confirma nem nega sua presença na imagem, essa deixa de ser uma questão nas imagens produzidas nas séries horror and surrealistic pictures e broken dolls. Extremamente relevantes para o estudo da obra Untitled \#264, essas imagens estão conectadas a ela em parte por conta da materialidade (no caso de horror and surrealistic pictures), em parte por conta da ausência da figura da artista. Em ambas as séries, os corpos artificiais derivados de manequins, próteses médicas, bonecas e bonecos dos mais diversos contêm a marca da artista apenas em seu arranjo. No que diz respeito a essa questão, Rosalind Krauss escreveu:

Deve haver muitas razões pelas quais [...] Sherman deu as costas ao seu próprio corpo como suporte para a imagem e começou a usar bonecas no lugar dele [...]. Em entrevistas, a artista discorreu sobre a tentativa de imaginar uma ruptura com sua própria presença constante em frente à câmera, possivelmente usando modelos, embora acabasse sempre dizendo que essa não era uma opção factível. Talvez ela finalmente tenha 
encontrado uma forma de fazê-lo factível; talvez a decisão de encenar a exibição de genitais e "atos sexuais" tenha sido de fato uma forma de forçar seu próprio corpo a sair da imagem, dando à Sherman a desculpa para usar algo substituto. Mas há muitos "talvez". Um outro talvez tenha a ver com como artistas se localizam em um universo do discurso. Algumas críticas de feministas ao trabalho de Sherman [...] têm como foco o silêncio da artista. [...] A ideia de que um(a) artista tem a responsabilidade de apresentar uma leitura explícita de seu trabalho parece tão peculiar quanto a ideia de que a única forma de produzir tal leitura - caso o(a) artista deseje fazê-lo - seja por meio de palavras. É muito mais usual para o(a) artista construir interpretações dentro do que estão produzindo e entender seus trabalhos situando-se em relação ao que o crítico Mikhail Bakhtin chamou de horizonte discursivo. O que significa dizer que o trabalho que um(a) artista faz entra, inevitavelmente, em um campo que é estruturado por outros trabalhos e sua interpretação: o(a) artista pode reforçar a interpretação dominante [...] ou resistir a ela e, consequentemente, criticá-la ${ }^{72}$.

Foi no início da década de 1990, com horror and surrealistic pictures e também com sex picutres, que, ainda segundo Krauss, o horizonte discursivo de Sherman apontou para Hans Bellmer e suas bonecas. "Sherman pode continuar a chamar seus trabalhos de Untitled, mas eles, todavia, produzem suas próprias leituras por meio de uma conexão com La Poupée de Bellmer"73.

Assim como Sherman foi acusada por feministas de alcançar sucesso com suas imagens em parte porque elas reiterariam e confirmariam a dominação masculina na sociedade (falocracia) ${ }^{74}$, Bellmer é constantemente acusado por ter produzido La poupée, pois o trabalho apresentaria "cenas de estupro e violência contra corpos femininos" 75 . Para Krauss, entretanto, o significante no trabalho de Bellmer é, entre outras coisas, partes de bonecas e não corpos reais, muito menos corpos como um todo. Além disso, para a crítica, seu significado não tem qualquer relação com vítimas de estupro, mas sim com o relacionamento do artista com o pai autoritário e nazista, membro de um partido que abraçava a ideia de "corpo perfeito do soldado treinado e do neoclassicismo endurecido" 76 .

Com base na ideia explorada por Hal Foster em seu artigo sobre o trabalho de Bellmer (escrito em 1991 e intitulado "Armor Fou") de que o fascismo precisaria de um corpo humano íntegro para servir de armadura contra aqueles que ameaçavam suas fronteiras seja "geograficamente (judeus, homossexuais, ciganos e bolcheviques), seja psicologicamente (o inconsciente, a sexualidade, o "feminino")" 77 , Krauss lê o trabalho de Bellmer como algo que assume a cumplicidade com o tema do fascismo apenas para expô-lo mais eficientemente ${ }^{78}$. Perverter bonecas pode ser visto, então, como uma maneira do artista se afastar do pai e de sua lei de forma agressiva. Outra visão é a de que Bellmer sentiria prazer em interagir com bonecas de maneira sádica, ao mesmo tempo em que 
se identificaria com seus corpos femininos fragmentados, por representarem seus medos mais profundos $^{79}$.

Mas se esses corpos femininos fragmentados de Bellmer são o oposto do corpo holístico do sujeito fascista blindado com uma armadura, a crítica Johanna Burton se pergunta "como poderiam se manifestar as representações agressivas [...] de (ou por) artistas mulheres se essa armadura é justamente imposta contra tudo o que é codificado como feminino?" ${ }^{80}$ Burton sugere, então, uma inversão em que "a armadura em si passaria a ser codificada como feminino [...] e que qualquer noção de um interior holístico seria necessariamente deslocada" ${ }^{81}$. Isso nos permitiria repensar os personagens de Sherman (de broken dolls ${ }^{82}$ à Untitled Film Stills, passando por sex pictures) como figuras que apresentam um tipo de "armadura feminina agressiva" 83 em vez de associá-los a padrões de passividade, o que acontece mesmo quando esses personagens são construídos para ir de encontro a esses padrões ${ }^{84}$.

É, portanto, da materialidade do corpo, tão patente no trabalho da artista, que Burton irá se servir para propor a releitura de toda obra de Sherman por meio de um olhar retrospectivo baseado no que a crítica chama de "corporeidade agressiva" 85 :

uma possibilidade habilitada por uma virada para o corpo, que talvez pudesse atravessar observador e objeto (ao mesmo tempo em que conecta um ao outro) de uma maneira diferente daquela presente em modelos em que o sujeito feminino é consumido/desfeito/dissolvido ${ }^{86}$.

Essa abordagem é extremamente fértil se pensarmos em Untitled \#264 como uma das muitas manifestações de um corpo agressivo na obra da artista. Ainda nos permite, por fim, retirar esse corpo das condições de passividade e objetificação impostas às representações do nu feminino ao longo da história da arte ocidental, um feito notável de uma obra cujo posicionamento em mais de uma série fotográfica de Sherman amplia suas possibilidades de fruição.

\section{REFERÊNCIAS}

BARROS, Roberta. Elogio ao toque ou como falar de arte feminista à brasileira. Rio de Janeiro: Ed. do Autor, 2016. 
BBC. Cindy Sherman - Nobody's Here But Me. 1994. (55m24s). Disponível em: $<$ https://www.youtube.com/watch?v=UXKNuWtXZ_U>. Acesso em: 02 mar. 2019.

BRYSON, Norman. House of Wax. In:

October Files \#6. Cambridge: MIT Press, 2006.

BURTON, JOHANNA (ed.), Cindy Sherman.

BURTON, Johanna. A body of slate: Cindy Sherman. In:

Cindy Sherman. October Files \#6. Cambridge: MIT Press, 2006.

BURTON, JOHANNA (ed.),

BURTON, Johanna. Cindy Sherman: abstraction and empathy. In:

RESPINI, Eva;

SHERMAN, Cindy; BURTON, Johanna. Cindy Sherman. Nova Iorque: The Museum of Modern Art, 2012.

BRITO, Ronaldo. Análise do Circuito. In: .FERREIRA, Glória(org.). Crítica de Arte no Brasil:

Temáticas Contemporâneas. Funarte. 2006.

CAIN, Abigail. A brief history of Cindy Sherman and feminism. Nova Iorque: Artsy Editorial, 2016

COTTON, Charlotte. Revivido e refeito. In:

Paulo: WMF Martins Fontes, 2010. P. 192 - 197. . A fotografia como arte contemporânea. São

FOSTER, Hal. Obscene, abject, traumatic. In:

Sherman. October Files \#6. Cambridge: MIT Press, 2006.

KRAUSS, Rosalind. Cindy Sherman: Untitled (1993). In:

Cindy Sherman. October Files \#6. Cambridge: MIT Press, 2006.

BURTON, JOHANNA (ed.),

LIST OF HIV-POSITIVE PEOPLE. Disponível em: < https://en.wikipedia.org/wiki/List_of_HIVpositive_people\#Visual_arts_and_fashion>. Acesso em: 10 de mar. 2019.

MOORHOUSE, Paul. Cindy Sherman. Nova Iorque: Phaidon, 2014.

MULVEY, Laura. Cosmetics and abjection: Cindy Sherman 1977 - 87. In: BURTON, JOHANNA (ed.), Cindy Sherman. October Files \#6. Cambridge: MIT Press, 2006.

RESPINI, Eva. Will the real Cindy Sherman please stand up? In: RESPINI, Eva; SHERMAN, Cindy; BURTON, Johanna. Cindy Sherman. Nova Iorque: The Museum of Modern Art, 2012.

SÍNDROME DA IMUNODEFICIÊNCIA ADQUIRIDA. Disponível em: $<$ https://pt.wikipedia.org/wiki/S\%C3\%ADndrome_da_imunodefici\%C3\%AAncia_adquirida $>$. Acesso em: 28 de fev. 2019.

THE PERFECT MOMENT. Disponível em: $<$ https://en.wikipedia.org/wiki/The_Perfect_Moment>. Acesso em: 28 de fev. 2019.

THORNTON, Sarah. O que é um artista? Rio de Janeiro: Zahar, 2015. 
WATERS, John. Cindy Sherman and John Waters: a conversation. In: RESPINI, Eva; SHERMAN, Cindy; BURTON, Johanna. Cindy Sherman. Nova Iorque: The Museum of Modern Art, 2012.

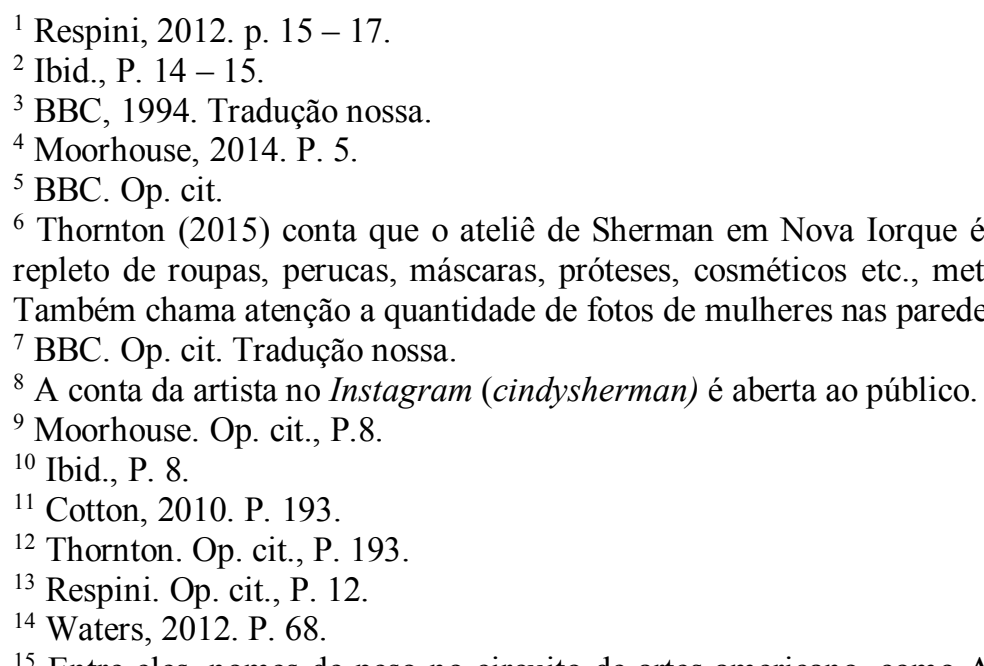

${ }^{15}$ Entre eles, nomes de peso no circuito de artes americano, como Arthur Danton, Rosalind Krauss, Craig Owens, Douglas Crimp, Hal Foster, Amanda Cruz e Norma Bryson (Ibid., P. 24 - 25 e 36), o que inegavelmente contribuiu para alavancar a carreira da artista, independentemente do conteúdo dos textos críticos, como frequentemente ocorre nesse meio (Brito, 2006. P. 263 - 264).

${ }^{16}$ Moorhouse. Op. cit., P.10.

${ }^{17}$ Respini. Op. cit., P. 7. Tradução nossa.

${ }^{18}$ Moorhouse. Op. cit., P.10. Tradução nossa.

${ }^{19}$ BBC. Op. cit. Tradução nossa.

${ }^{20}$ Respini. Op. cit., P. 18.

${ }^{21}$ Schwabsky, 1999.

22 Respini. Op. cit, P. 248.

${ }^{23} \mathrm{O}$ termo aparece aqui no masculino por ser esse um papel majoritariamente exercido por homens à época.

${ }^{24}$ Sherman foi acusada de enfraquecer a causa feminista ao retratar personagens femininos em poses vulneráveis, que aludem a situações de extrema intimidade, constrangimento, humilhação, abuso e violência, como as vividas em relações amorosas, sequestros e, até, estupros (Cain, 2016).

${ }^{25}$ Respini. Op. cit., P. 36.

${ }^{26}$ Ibid., P. 35.

${ }^{27}$ Waters. Op. cit., P. 74.

${ }^{28}$ BBC. Op. cit.

${ }^{29}$ Respini. Op. cit., P. 36. Tradução nossa.

${ }^{30}$ BBC. Op. cit. Tradução nossa.

${ }^{31}$ Este trabalho considera "sistema de artes" o conjunto dos seguintes agentes e seus inter-relacionamentos: artista, obra, curador, marchand, galeria, público, crítica, mercado, colecionador, museu e historiador.

${ }^{32}$ Waters. Op. cit., P. $69-70$.

${ }^{33}$ Ibid., P. 37.

${ }^{34}$ Ibid., P. 75.

${ }^{35}$ Esses catálogos vendiam próteses destinadas especialmente a estudantes de medicina, para o uso em práticas fora do universo da autópsia, o que fascinou enormemente a artista. (BBC. Op. cit.).

${ }^{36}$ Respini. Op. cit., P. 37.

${ }^{37}$ Waters. Op. cit., P. 70. 


38 SÍNDROME DA IMUNODEFICIÊNCIA ADQUIRIDA. Disponível em:
$<$ https://pt.wikipedia.org/wiki/S\%C3\%ADndrome_da_imunodefici\%C3\%AAncia_adquirida $>$. Acesso em: $28 \mathrm{de}$ fev. 2019.

${ }^{39}$ Dentre eles, Félix González-Torres, Robert Mapplethorpe, Peter Hujar, David Wojnarowicz e Keith Haring (LIST OF HIV-POSITIVE PEOPLE. Disponível em: <https://en.wikipedia.org/wiki/List_of_HIVpositive_people\#Visual_arts_and_fashion>. Acesso em: 10 de mar. 2019).

${ }^{40}$ Barros, 2016. P. 205.

${ }^{41}$ Uma campanha iniciada pelo grupo American Family Association (AFA) contra o que consideravam "arte indecente" acendeu um intenso debate sobre incentivo público à arte com conteúdo sexual que ganhou as primeiras páginas dos jornais americanos (THE PERFECT MOMENT. Disponível em: $<$ https://en.wikipedia.org/wiki/The_Perfect_Moment>. Acesso em: 28 de fev. 2019).

${ }^{42}$ Respini. Op. cit., P. 37.

${ }^{43}$ BBC. Op. cit. Tradução nossa.

${ }^{44}$ Waters. Op. cit., P. 77. Tradução nossa.

${ }^{45}$ Burton, 2006. P. 201.

${ }^{46}$ Waters. Op. cit., p. 78.

47 "Enquanto produzia esse trabalho [a série masks], Sherman registrou seu interesse em Sade e sua própria tentativa (em sua visão, malsucedida) de explorar uma direção violenta e misógina, à la Sade e os garotos". (Burton. Op. cit., P. 201).

${ }^{48}$ Moorhouse. Op. cit., P. 103.

${ }^{49}$ Moorhouse afirma que há também registros no caderno da artista de que ela estaria interessada nesses trabalhos (Ibid., P. 103).

${ }^{50}$ Ibid, P. 103.

${ }^{51}$ Burton. Op. cit., P. 201.

${ }^{52}$ Moorhouse. Op. cit., P. 104.

${ }_{53}^{53}$ Burton, 2012. P. $55-56$.

${ }^{54}$ Krauss, 2006. P. $97-141$.

${ }_{55}^{55}$ Falarei sobre a ideia de significante abordada por Krauss na obra de Cindy Sherman mais adiante neste capítulo.

${ }^{56}$ Krauss. Op. cit., P. 137. Tradução nossa.

${ }^{57}$ Mulvey, 2006. P. $65-82$.

${ }^{58}$ Ibid., P. 76.

${ }^{59}$ Ibid., P. 67.

${ }^{60}$ Bryson, 2006. P. $83-96$.

${ }^{61}$ Burton, 2006. P. $193-215$.

${ }^{62}$ Ibid., P. 195. Tradução nossa.

${ }^{63}$ Aqui, acompanho a noção de significante como "forma de expressão", proposição feita por Rosalind Krauss em seu ensaio supracitado com base na pesquisa de Roland Barthes em seu livro Mythologies (Krauss. Op. cit., P. 99).

${ }^{64}$ Krauss. Op. cit., P. 114.

${ }^{65}$ Ibid., P. 117.

${ }^{66}$ Waters. Op. cit., P. 73.

${ }^{67}$ Ibid., P. 73.

${ }^{68}$ Foster, 2006. P. 175. Tradução nossa.

${ }^{69}$ Mulvey. Op. cit., P. 74. Tradução nossa.

${ }^{70}$ Krauss. Op. cit., P. 126. Tradução nossa.

${ }^{71}$ Burton, 2006. Op. cit., P. 201.

${ }^{72}$ Krauss. Op. cit., P. 133 - 134. Tradução nossa.

${ }^{73}$ Ibid., P. 134. Tradução nossa.

${ }^{74}$ Ibid., P. 133.

${ }^{75}$ Ibid., P. 134. Tradução nossa.

${ }^{76}$ Ibid., P. 136. Tradução nossa.

${ }^{77}$ Ibid., P. 136. Tradução nossa.

${ }^{78}$ Ibid., P. 136. 
${ }^{79}$ Burton, 2006. P. $197-198$.

${ }^{80}$ Ibid., P. 198. Tradução nossa.

${ }^{81}$ Ibid., P. 198. Tradução nossa.

82 Vale considerar que, quando Burton escreveu seu artigo, a série broken dolls já havia sido produzida e exibida. Burton é, inclusive, uma das poucas teóricas que cita esse "criticamente esquecido" trabalho, em que só haveria lugar para "efeitos literais, talvez perturbadores, de um tipo de jogo misógino fracassado", uma vez que foi jogado apenas com objetos, sem a presença de qualquer sujeito na imagem, ainda que corpos inanimados estejam ali (Ibid., P. 201).

${ }^{83}$ Ibid., P. 198. Tradução nossa.

${ }^{84}$ Ibid., P. 198.

${ }^{85}$ Ibid., P. 196. Tradução nossa.

${ }^{86}$ Ibid., P. 207. Tradução nossa. 